\title{
Salmonella enterica Serovar Typhimurium Exploits Inflammation to Modify Swine Intestinal Microbiota
}

\author{
Rosanna Drumo ${ }^{1,2 \dagger}$, Michele Pesciaroli ${ }^{1,3}$, Jessica Ruggeri ${ }^{4}$, Michela Tarantino ${ }^{1}$, \\ Barbara Chirullo ${ }^{1}$, Claudia Pistoia ${ }^{1}$, Paola Petrucci ${ }^{1}$, Nicola Martinelli ${ }^{4}$, Livia Moscati ${ }^{5}$, \\ Elisabetta Manuali ${ }^{5}$, Silvia Pavone ${ }^{5}$, Matteo Picciolini ${ }^{6}$, Serena Ammendola ${ }^{7}$, \\ Gianfranco Gabai ${ }^{2}$, Andrea Battistoni ${ }^{7}$, Giovanni Pezzotti ${ }^{5}$, Giovanni L. Alborali ${ }^{4}$, \\ Valerio Napolioni ${ }^{6}$, Paolo Pasquali ${ }^{1 *}$ and Chiara F. Magistrali ${ }^{5 *}$
}

${ }^{1}$ Department of Veterinary Public Health and Food Safety, Istituto Superiore di Sanità, Rome, Italy, ${ }^{2}$ Department of Comparative Biomedicine and Food Science, University of Padua, Padua, Italy, ${ }^{3}$ VISAVET Health Surveillance Centre, Universidad Complutense Madrid, Madrid, Spain, ${ }^{4}$ Department of Veterinary Diagnostic, Istituto Zooprofilattico Sperimentale della Lombardia e dell'Emilia Romagna, Brescia, Italy, ${ }^{5}$ Research and Development Area, Istituto Zooprofilattico Sperimentale dell'Umbria e della Marche, Perugia, Italy, ${ }^{6}$ Department of Experimental Medicine, University of Perugia, Perugia, Italy, ${ }^{7}$ Department of Biology, University of Roma Tor Vergata, Rome, Italy

\section{OPEN ACCESS}

Edited by:

D. Scott Merrell,

Uniformed Services University, USA

Reviewed by: Richard E. Isaacson,

University of Minnesota, USA Johanna R. Elfenbein, North Carolina State University, USA

${ }^{*}$ Correspondence: Paolo Pasquali paolo.pasquali@iss.it:

Chiara F. Magistrali c.magistrali@izsum.it

${ }^{\dagger}$ These authors have contributed equally to this work

Received: 12 September 2015 Accepted: 28 December 2015 Published: 22 January 2016

Citation:

Drumo R, Pesciaroli M, Ruggeri J, Tarantino M, Chirullo B, Pistoia C, Petrucci P, Martinelli N, Moscati L, Manuali E, Pavone S, Picciolini M, Ammendola S, Gabai G, Battistoni A, Pezzotti G, Alborali GL, Napolioni V, Pasquali $P$ and Magistrali CF (2016)

Salmonella enterica Serovar Typhimurium Exploits Inflammation to Modify Swine Intestinal Microbiota. Front. Cell. Infect. Microbiol. 5:106. doi: 10.3389/fcimb.2015.00106
Salmonella enterica serovar Typhimurium is an important zoonotic gastrointestinal pathogen responsible for foodborne disease worldwide. It is a successful enteric pathogen because it has developed virulence strategies allowing it to survive in a highly inflamed intestinal environment exploiting inflammation to overcome colonization resistance provided by intestinal microbiota. In this study, we used piglets featuring an intact microbiota, which naturally develop gastroenteritis, as model for salmonellosis. We compared the effects on the intestinal microbiota induced by a wild type and an attenuated $S$. Typhimurium in order to evaluate whether the modifications are correlated with the virulence of the strain. This study showed that Salmonella alters microbiota in a virulence-dependent manner. We found that the wild type S. Typhimurium induced inflammation and a reduction of specific protecting microbiota species (SCFA-producing bacteria) normally involved in providing a barrier against pathogens. Both these effects could contribute to impair colonization resistance, increasing the host susceptibility to wild type S. Typhimurium colonization. In contrast, the attenuated S. Typhimurium, which is characterized by a reduced ability to colonize the intestine, and by a very mild inflammatory response, was unable to successfully sustain competition with the microbiota.

Keywords: Salmonella Typhimurium, microbiota, inflammation, immune response, pig, salmonellosis

\section{INTRODUCTION}

Nontyphoidal salmonellae (NTS) as Salmonella enterica serovar Typhimurium are a leading cause of acute food-borne zoonoses worldwide being responsible for hundreds of millions of cases of gastroenteritis and bacteremia annually (Hohmann, 2001). Pigs are important reservoir of infection for humans as they are asymptomatic carriers of broad host-range serovars of Salmonella (Funk and Gebreyes, 2004; Pires et al., 2011). The intestine is considered to be the biological niche of 
Salmonella with the intestinal mucosa having a central role in regulating the immune response to bacteria (Hallstrom and McCormick, 2011). However, Salmonella has developed strategies to overcome and cope with most of the immune defenses developed by the host (Behnsen et al., 2015). Examples of the strategies used by Salmonella to evade mucosal innate immunity include the ability to resist to the reactive oxygen species generated during inflammation (Bogomolnaya et al., 2013), in order to produce energy by an anaerobic respiration chain which uses an electron acceptor specifically generated in the gut under oxidative stress (Winter et al., 2010) and to resist to the sequestration of essential nutrients such as iron and zinc (Raffatellu et al., 2009; Liu et al., 2012). As a matter of fact, the ability to resist to the antimicrobial host responses characterizing gut inflammation promotes the growth of Salmonella in the intestinal lumen over the competing microbiota. During the past few years, there has been an expanding interest concerning the role played by intestinal microbiota in the susceptibility to enteric pathogens. Microbiota contributes to the digestion of dietary substances and to the synthesis of essential food supplements such as vitamins, and to the development or maintenance of the mucosal immune system (Littman and Pamer, 2011). Moreover, it acts as a barrier against invading bacteria both physically, blocking pathogen access to the epithelial layer, and also by outcompeting for nutrients reducing the survival and invasiveness of enteric pathogens (Hallstrom and McCormick, 2011; Sassone-Corsi and Raffatellu, 2015). However, it has been known that $S$. Typhimurium requires intestinal inflammation to circumvent "colonization resistance" provided by the intestinal microbiota (Santos et al., 2009). It has been shown that Salmonella can alter the normal composition of the gut microbiota, and this influence is associated with Salmonella virulence factors that induce inflammatory mucosal host responses (Barman et al., 2008). Furthermore, animals with disrupted microbiota have an increased susceptibility to infection (Barman et al., 2008; Juricova et al., 2013). Most of the studies examining salmonellosis have been carried out in murine models that naturally do not develop gastroenteritis. To resemble the disease in humans, mice can be subjected to antibiotic treatment in order to eliminate microbiota and to develop colitis (Ahmer and Gunn, 2011). Therefore, due to the lack of an intact microbiota, murine models are not suitable for the comprehension of the mechanisms used by Salmonella to thrive in the gastrointestinal environment (Elfenbein et al., 2013). To circumvent this limitation, we chose the pig as a model for our study. The advantage of the pig lies in the great similarity between humans and pigs in the gastrointestinal tract and in the disease caused by Salmonella as well as being a natural host of Salmonella (Zhang et al., 2013). We hypothesized that the Salmonella virulence degree is a determining factor in influencing the capability of the pathogen to overcome protective microbiota. To explore this, we compared the effects on the intestinal microbiota of S. Typhimurium wild type to that of an attenuated Salmonella strain lacking the ZnuABC transporter. Our findings provide evidence that the microbiota modifications induced by Salmonella are correlated with the virulence of the strain. Moreover, Salmonella could overcome colonization resistance through the reduction of microbiota members normally involved in the intestinal homeostasis and in the inhibition of pathogen growth.

\section{MATERIALS AND METHODS}

\section{Salmonella spp. Cultures}

The wild-type strain S. Typhimurium ATCC 14028 (hereafter $\mathrm{STM}^{\mathrm{wt}}$ ) and its isogenic attenuated $z n u A B C$ mutant (hereafter $\mathrm{STM}^{\triangle \mathrm{znuABC}}$; Ammendola et al., 2007), were used throughout the study. Strains were grown overnight at $37^{\circ} \mathrm{C}$ in Brain Heart Infusion broth (Oxoid Ltd., Basingstoke, UK), harvested by centrifugation and washed twice in ice-cold phosphate buffer solution (PBS) (Sigma-Aldrich, Milan, Italy).

\section{Animals and Samples Collection}

Thirty-one post weaned piglets old 28 days, from Salmonella-free sows (routinely monitored with microbiological and serological tests), were used in the experiment. Group A ( 9 piglets) received sterile sodium bicarbonate buffer and it was used as naïve control group. Groups B and C (11 piglets each) were orally infected with $20 \mathrm{ml}$ of sterile $10 \%$ sodium bicarbonate buffer containing $2 \times 10^{9} \mathrm{CFU}$ of STM ${ }^{\triangle \mathrm{znuABC}}$ (Group B) or $2 \times 10^{9} \mathrm{CFU}$ of STM $^{\mathrm{wt}}$ (Group C). At 0, 1, 2, 7, and 12 days post infection (dpi), rectal temperature was recorded and serum and fecal samples were collected to evaluate TNF- $\alpha$, IL1- $\alpha$, haptoglobin, and CRP production and to detect fecal excretion of Salmonella, respectively. Four piglets of group $\mathrm{A}$ and 5 for groups $\mathrm{B}$ and $\mathrm{C}$ were sacrificed at $1 \mathrm{dpi}$, while 5 piglets of group A and 6 for groups B and C at 12 dpi. Portions of spleen, ileum, cecum, colon, ileocecal lymph nodes, and tonsil of the soft palate were taken for microbiological analysis, histology, and for mRNA isolation. Feces and cecal and colonic contents were collected to analyze the microbiota composition.

All the experiments were authorized by national authority and conducted according to European Directive (2010/63/EU; approval number 54/2012).

\section{Microbiology}

Fecal shedding and organs colonization of STM ${ }^{\mathrm{wt}}$ and $\mathrm{STM}^{\triangle \mathrm{znuABC}}$ were determined according to the ISO 6579: 2002/Amendment 1:2007 protocol. Briefly, samples were weighed and homogenized in nine parts of Buffered Peptone Water (BPW) (Oxoid Ltd., UK). This initial solution was then used to perform a decimal dilution series carried out by systematically transferring an aliquot of $0.5 \mathrm{ml}$ of each successive dilution in $4.5 \mathrm{ml}$ of BPW. All BPW-diluted samples were incubated at $37^{\circ} \mathrm{C}$ for $18 \pm 3 \mathrm{~h}$. $0.1 \mathrm{ml}$ of cultures were subsequently seeded on Modified Semisolid RappaportVassiliadis (MSRV) agar plates (Oxoid Ltd., UK) and incubated at $41.5^{\circ} \mathrm{C}$ for $24 \mathrm{~h}$ for the selective enrichment of Salmonella. A loopful of growth from each MSRV plate was streaked onto Xylose-Lysine-Desoxycholate Agar (Oxoid Ltd., UK) and Brilliant Green Agar (Oxoid Ltd., UK) plates and hence incubated at $37^{\circ} \mathrm{C}$ overnight. Suspect Salmonella colonies were subjected to biochemical identification by the BBL Enterotube II 
(BD Franklin Lakes, USA) and serological identification using Salmonella group-specific antisera (Remel, Lenexa, USA). This is a semi-quantitative approach that allows the quantification of Salmonella in a sample within a tenfold band (detection limit 1 $\mathrm{CFU} / \mathrm{g}$ feces).

\section{Histology}

Tissue samples of cecum were fixed in formalin, embedded in paraffin wax and stained with hematoxylin, and eosin according to standard procedures.

\section{Immune Mediators Production}

TNF- $\alpha$, IL1- $\alpha$, haptoglobin, and C-reactive Protein (CRP) production was measured in serum samples from animals bled at 1 and 12 dpi using a sandwich ELISA (Porcine Quantikine ELISA Kit, R\&D System, Mn, USA), according to the producer's instructions.

\section{Gene Expression}

Total RNA was extracted from sections of the cecum, colon, and ileocecal lymph nodes using the PureLink RNA Mini Kit (Ambion, Life Technologies). Reverse transcription of $1 \mu \mathrm{g}$ of RNA was performed for each individual sample using Tetro cDNA Synthesis Kit (Bioline) and $5 \mu \mathrm{l}$ of cDNA were used for real-time reaction using SensiMix II Probe Kit (Bioline). Primers for cytokines (RPL-32, IL- $1 \alpha$, IL- $1 \beta$, TNF- $\alpha$, and IFN- $\gamma$ ) were designed using PrimerQuest Design Tool (Integrated DNA Technologies, IDT; see Supplementary Table 1). Fold changes in gene expression were calculated using the $\Delta \Delta \mathrm{Ct}$ method in comparison to the results for the reference housekeeping gene RPL32.

\section{Fecal 16S rDNA Metagenomics Next-Generation Sequencing}

Bacterial genomic DNA (gDNA) was extracted from feces, cecal, and colonic contents using QIAmp DNA Stool Mini Kit (Qiagen, Hilden, Germany). Fifty nanograms of gDNA were used to amplify by PCR the hypervariable V3-V4 regions of the $16 \mathrm{~S}$ rDNA using bacteria/archeal primers 515F/806R with Illumina overhang adapters (Caporaso et al., 2012). One nanogram of PCR amplicon was used for each sample to prepare the sequencing library according to the Illumina Nextera XT DNA Sample Preparation Kit. During this procedure, using a limited cycle PCR, Illumina sequencing adapters, and dual-index barcodes were added to the amplicon. All the libraries were subsequently normalized and pooled by 24 prior to sequencing according to manufacturer's instructions (Illumina Nextera XT DNA Library Preparation Guide). Each pool of 24 samples was sequenced on Illumina MiSeq using a $2 \times 250$ paired-end (PE) setting on a standard MiSeq flow cell. Sequencing reads were trimmed and all the reads with a quality score below the Q20 parameters were discarded from the analysis. Then, all the PE reads were joined using the join_paired_ends scripts of QIIME utilities (Caporaso et al., 2010) to create longer fragments. The Lederhosen pipeline (based on UCLUST software and green genes v $13.516 \mathrm{~S}$ database) was used to create the OTU table for each sample. The OTU tables were provided as input for the MatR package to remove singletons and to normalize the data by sequencing depth. Alphaand beta- diversity were determined by QIIME using Shannon's and Fisher's indices for alpha diversity, unweighted Unifrac and Bray-Curtis for beta diversity, respectively.

\section{Quantitative Real-Time PCR of 16S rRNA Gene Sequences}

q-PCR was performed using bacterial groups-specific $16 \mathrm{~S}$ rRNA primers (see Supplementary Table 2) to determine the amount of bacteria in the study groups. However, this method is an approximation of microbial abundance as a great amount of bacteria features many copies of the $16 \mathrm{~S}$ gene. Therefore, both variation in the abundance of organisms and genomic copy number variation can influence the quantitative prediction of $16 \mathrm{~S}$ gene abundances. Real time PCRs were carried out on SensiMix SYBR Low-ROX Kit (Bioline). The amplification program started with an initial step at $95^{\circ} \mathrm{C}$ for $10 \mathrm{~min}$, followed by 40 cycles of $15 \mathrm{~s}$ each at $95^{\circ} \mathrm{C}, 15 \mathrm{~s}$ at $55^{\circ} \mathrm{C}-63^{\circ} \mathrm{C}$ (depends on the $\mathrm{Tm}$ of primers), and $15 \mathrm{~s}$ at $72^{\circ} \mathrm{C}$. The $16 \mathrm{~S}$ gene copy numbers per $\mu l$ of DNA, from each sample, were determined by using standard curves generated from fragments of $16 \mathrm{~S}$ rRNA genes of reference bacteria specific for each group cloned into plasmid (Promega) as templates. The plasmid was purified by using the Wizard Plus SV Minipreps DNA purification kit (Promega) and its concentration was quantified by using a NanoDrop ${ }^{\circledR}$ ND1000 Spectrophotometer. With the molecular weight data of the plasmid and insert sequences, the copy number ( $\mathrm{g} /$ molecule) was calculated according to the equation defined by Whelan et al. (2003). For each microbial population, the corresponding plasmid was chosen to create a 10 -fold standard curve ranged from $10^{8}$ to $10^{2}$ copies. Copy numbers of $16 \mathrm{~S}$ rRNA genes per $\mu \mathrm{l}$ of sample (feces, caecal, and colonic contents) were transformed into logarithms to achieve normal distribution, and the mean \pm standard deviation was calculated. To estimate the copy number of Enterobacteriaceae other than Salmonella, for each sample the Salmonella $16 \mathrm{~S}$ gene copy number was subtracted from the total Enterobacteriaceae 16S gene copy number.

\section{Statistical Analysis}

Statistical analysis was performed using GraphPad 6.0 software for Windows (GraphPad Software Inc.; San Diego; CA). Microbiota analysis by q-PCR were estimated using oneway analysis of variance (One-way ANOVA). Fecal shedding, organs colonization, and cytokines expression were analyzed using non-parametric Mann-Whitney test. Differences in body temperature and differences between groups in the TNF$\alpha$, IL1- $\alpha$, haptoglobin, and CRP production were estimated using non-parametric Dunn's test. Moreover, non-parametric Kruskal-Wallis was used to test the presence of significant differences among the sample groups analyzed for each different taxonomical level considered (Phylum, Family, Genus) and Benjamini-Hochberg FDR was applied to correct multiple testing. A $P \leq 0.05$ was considered statistically significant. Nonparametric Dunn's test was also used to estimate differences in alfa diversity. 


\section{RESULTS}

\section{Pathogenicity of Salmonella Typhimurium is Positively Correlated to Bacterial Virulence}

Piglets infected with STM ${ }^{\triangle \mathrm{znuABC}}$ (group B) and STM ${ }^{\mathrm{wt}}$ (group C) had a transient increase in body temperature at $1 \mathrm{dpi}$ compared with naïve controls (group A). At $2 \mathrm{dpi}$, only the group C $\left(\mathrm{STM}^{\mathrm{wt}}\right)$ continued showing a significantly higher body temperature than group A (Figure 1A). Moreover, differences in the levels of Salmonella fecal shedding were observed among the study groups. Animals infected with STM ${ }^{\mathrm{wt}}$ and $\mathrm{STM}^{\mathrm{\Delta znuABC}}$ started to shed bacteria the day after experimental infection and reached the peak of excretion at $2 \mathrm{dpi}$. However, unlike group C $\left(\mathrm{STM}^{\mathrm{wt}}\right)$ that continued shedding a similar amount of bacteria throughout the whole period of observation, group B $\left(\mathrm{STM}^{\triangle \mathrm{znuABC}}\right.$ ) showed a sharp decline over time (Figure 1B). To further assess the inflammatory response induced by STM ${ }^{\mathrm{wt}}$ and $\mathrm{STM}^{\triangle \mathrm{ZnuABC}}$, piglets were bled at different time points and haptoglobin, CRP, IL1- $\alpha$, and TNF- $\alpha$ levels were measured in sera. Group C $\left(\mathrm{STM}^{\mathrm{wt}}\right)$ had an early immune response characterized by a significant increase of haptoglobin and IL1- $\alpha$ at $2 \mathrm{dpi}$, and TNF- $\alpha$ at 2 and $7 \mathrm{dpi}$, followed by a late production of CRP which reached a significant level at $12 \mathrm{dpi}$. Conversely, group $B\left(\mathrm{STM}^{\triangle \mathrm{znuABC}}\right)$ did not show any different production of haptoglobin, CRP, IL1- $\alpha$, and TNF- $\alpha$ when compared with the naïve (group A; Figure 2). Piglets of different groups were euthanized at 1 and 12 dpi to assess bacterial colonization of organs. As shown in Figure 3, colonization occurred as early as $1 \mathrm{dpi}$, either in gut or in systemic organs. However, piglets infected with STM ${ }^{\text {wt }}$ (group C) showed a significant higher degree of colonization than piglets infected with $\mathrm{STM}^{\triangle \mathrm{znuABC}}$ (group B) in the gut organs $(p<0.05)$ at $1 \mathrm{dpi}$ (Figure 3) and in the colon $(p<0.05)$ at 12 dpi (Supplementary Figure 1). Organs samples taken from naïve animals (group A) were negative.

These findings confirm that $\mathrm{STM}^{\mathrm{wt}}$ and $\mathrm{STM}^{\triangle \mathrm{znuABC}}$ have a differential colonization efficiency. Moreover, $\mathrm{STM}^{\triangle \mathrm{znuABC}}$ did not show a significant systemic inflammation. We could infer that these results are a direct consequence of the intrinsic incapability of STM ${ }^{\triangle \mathrm{ZnuABC}}$ to induce an inflammatory response but, in alternative, they could be due to the lower colonization of STM ${ }^{\triangle \mathrm{znuABC}}$ which is not sufficient to give rise to a systemic immune response.

\section{Histology}

We compared the cecum histopathological findings from control, $\mathrm{STM}^{\triangle \mathrm{znuABC}}$ and STM ${ }^{\mathrm{wt}}$-infected piglets at 1 and $12 \mathrm{dpi}$. At $1 \mathrm{dpi}$, sections from control piglets did not show inflammatory infiltrate (Figure 4A); conversely, piglets infected with STM ${ }^{\triangle \mathrm{znuABC}}$ and $\mathrm{STM}^{\mathrm{wt}}$ showed neutrophilic infiltrate in the lamina propria and submucosa (Figures 4B,C). The neutrophilic infiltrate appeared moderate and multifocal in the $\mathrm{STM}^{\triangle \mathrm{znuABC}}$ (Figure 4B), with crypt abscess formation, whereas marked and diffused in the STM $^{\text {wt }}$ infected piglets (Figure 4C). On the other hand, the neutrophil inflammation was mild at $12 \mathrm{dpi}$ and present in a multifocal pattern in piglets infected with $\mathrm{STM}^{\triangle \mathrm{znuABC}}$, while inflammation was mild and diffuse in piglets infected with STM $^{\text {wt }}$ (data not shown). Overall, a histological investigation indicated the presence of inflammatory infiltrate only in STM ${ }^{\mathrm{wt}}$ and $\mathrm{STM}^{\triangle \mathrm{znuABC}}$. A higher degree of inflammation was observed in piglets infected with STM ${ }^{\mathrm{wt}}$.
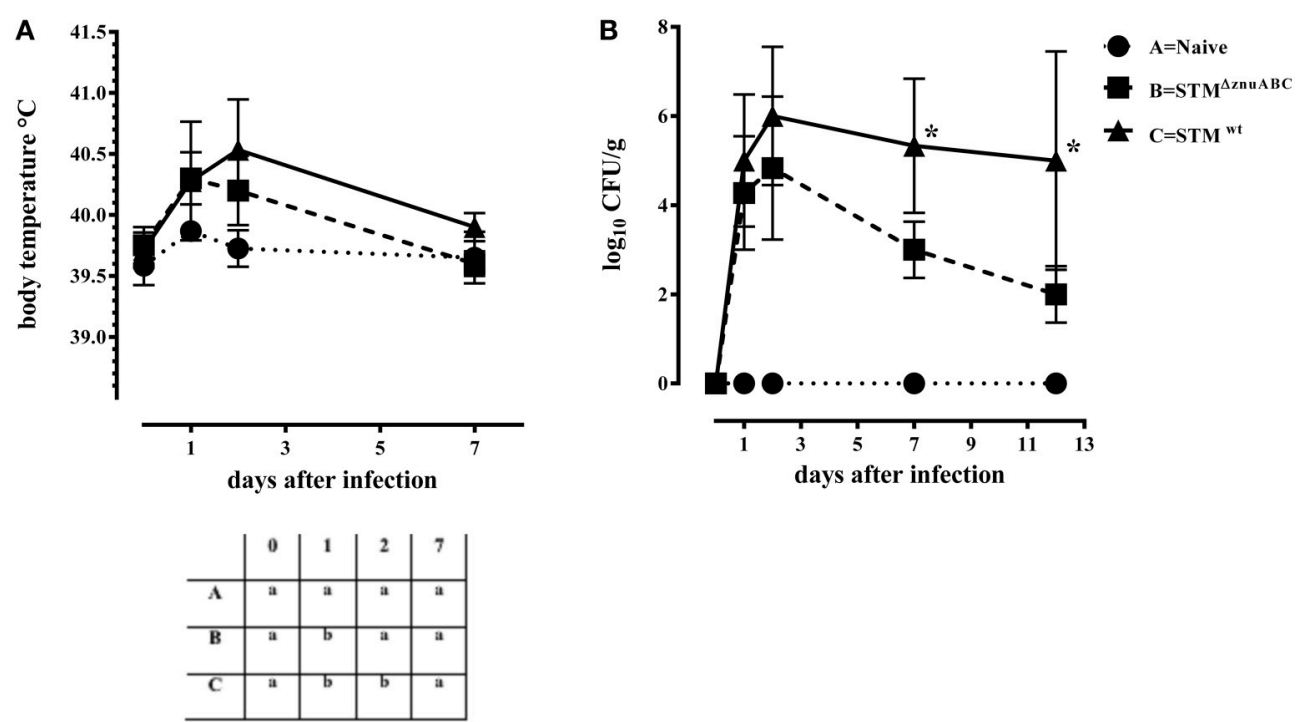

FIGURE 1 | STM ${ }^{\Delta z n u A B C}$ (group B) shows a lower virulence in piglets compared to the STMwt (group C). (A) Mean values and standard deviation (SD) bars of body temperature of study groups in different time points. In the table on the bottom the levels of significance were reported among groups at different time points. Different letters at each time point represent significant different results ( $P \leq 0.05$, Dunn's test). (B) Mean values and SD bars of CFU/g of STM $\Delta$ znuABC and STMwt shed in feces. Results of piglets infected with STM ${ }^{\Delta \text { znuABC }}$ were compared to results of STM ${ }^{w t}$ and differences were statistically significant when ${ }^{*} P \leq 0.05$, Mann-Whitney test. 

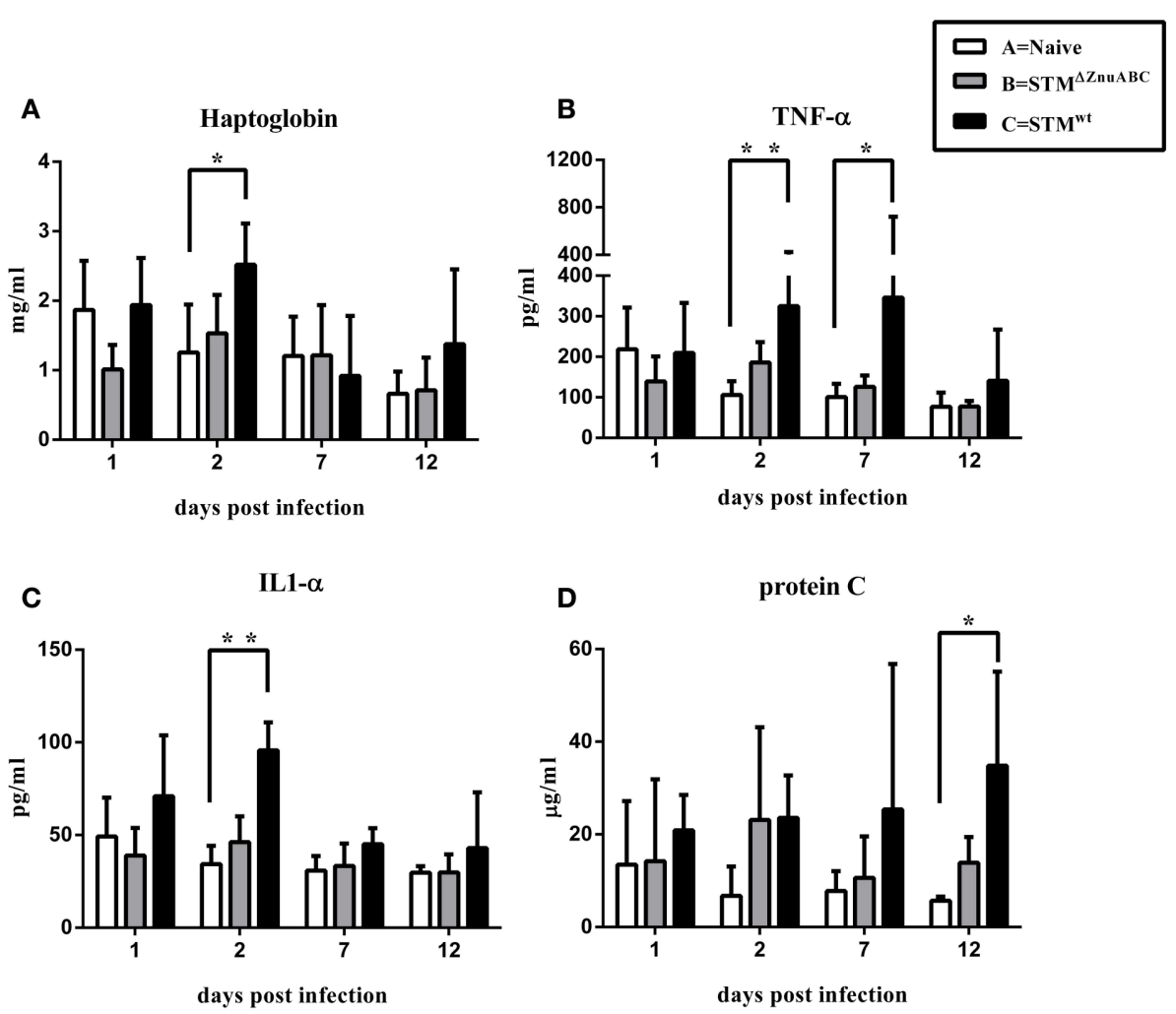

FIGURE 2 | (A-D) S. Typhimurium induces an inflammatory response correlated to the virulence of the bacterial strain. Haptoglobin, TNF- $\alpha$, IL1- $\alpha$, and C-reactive protein levels in serum of animals were determined by ELISA. The asterisks indicate statistical significance: ${ }^{*} P \leq 0.05$ and ${ }^{\star *} P \leq 0.01$ (multiple comparisons-Dunn's test).

\section{Influence of Salmonella Infection on the Expression of Pro-Inflammatory Cytokines}

Pro-inflammatory (IL1- $\alpha$, IL1- $\beta$, TNF- $\alpha$ ) and regulatory (IFN$\gamma)$ cytokines were observed so as to evaluate the early immune response in the ileocecal lymph nodes, colon, and cecum at 1 and 12 dpi (Figures 5A-H; Supplementary Figures 2A-H, 3A,B). At $1 \mathrm{dpi}$, we observed a tendency of the pro-inflammatory cytokines to increase in all organs analyzed; however, only the increase of IL1- $\beta(p<0.05)$ in the cecum and in the colon, and IL1- $\alpha(p<$ $0.05)$ in the lymph nodes of group $C\left(S^{2} M^{\mathrm{wt}}\right)$ were statistically significant (Figures 5A-C; Supplementary Figures 2A-C, 3A-C). At 12 dpi, overall expression of IL1- $\alpha$, IL1- $\beta$, and TNF- $\alpha$ returned to baseline levels (Figures 5E-G; Supplementary Figures 2E-G, $3 \mathrm{E}-\mathrm{G})$. Moreover, TNF- $\alpha(p<0.01)$, IL1- $\beta(p<0.01)$, and IL1- $\alpha(p<0.05)$ were significantly down-regulated in the colon of piglets infected with STM ${ }^{\triangle \mathrm{znuABC}}$ (group B; Supplementary Figures $2 \mathrm{E}-\mathrm{G})$, and IL1- $\alpha(p<0.05)$ also in the lymph nodes of group C (STM ${ }^{\mathrm{wt}}$; Supplementary Figures $\left.3 \mathrm{E}-\mathrm{G}\right)$.

\section{S. Typhimurium Alters Composition of the Microbiota in the Post-Weaned Piglets Model}

Aiming to more specifically analyze the impact of STM ${ }^{\mathrm{wt}}$ and $\mathrm{STM}^{\triangle \mathrm{znuABC}}$ on some of the most representative bacterial members, we used quantitative real time PCR (q-PCR). As depicted in Figure 6, consistent changes in the microbiota were present primarily in the cecal contents at 1 day post-Salmonella infection, with a significant increase of total 16S rRNA gene copies (representative of total bacterial numbers) in piglets infected with STM ${ }^{\mathrm{wt}}$ (group C; $p<0.05$ ) compared to naïve animals (group A) and piglets infected with STM ${ }^{\triangle \text { znuABC }}$ (group $\mathrm{B} ; p<0.05)$. Differences in the Lactobacillus/Lactococcus group were statistically significant between groups B and C $(p<0.05)$ and very close to significance between groups A (naïve) and $C$ $\left(\mathrm{STM}^{\mathrm{wt}}\right.$ ) in the cecum (Figure 6A). In the feces (Supplementary Figure 4), the Lactobacillus/Lactococcus group showed significant differences at $1,2,7$, and $12 \mathrm{dpi}(p<0.05)$ between groups $\mathrm{A}$ and $\mathrm{C}$, and only at $12 \mathrm{dpi}$ between groups B and $\mathrm{C}(p<$ 0.05; Supplementary Figure 4). A decrease in the Eubacterium rectale/Clostridium coccoides group was evident in group $\mathrm{C}(p<$ $0.05)$ at $12 \mathrm{dpi}$ in the cecum and at $2 \mathrm{dpi}$ in the feces $(p<0.01$; Figure 6B; Supplementary Figure 4C). No differences among the three experimental groups were observed for Bacteroides in any of the samples analyzed. Conversely, at $1 \mathrm{dpi}$ an evident increase in the Bifidobacterium group was observed in all the districts investigated between groups A and $\mathrm{C}$ ( $p<0.01$ for cecal content and $p<0.001$ for colon and feces) and between groups $\mathrm{B}$ and $\mathrm{C}$ $(p<0.01$; Figure 6A; Supplementary Figures 4B, 5A). At 12 dpi, the Bifidobacterium group showed a sharp reduction in groups 


\section{1 dpi}
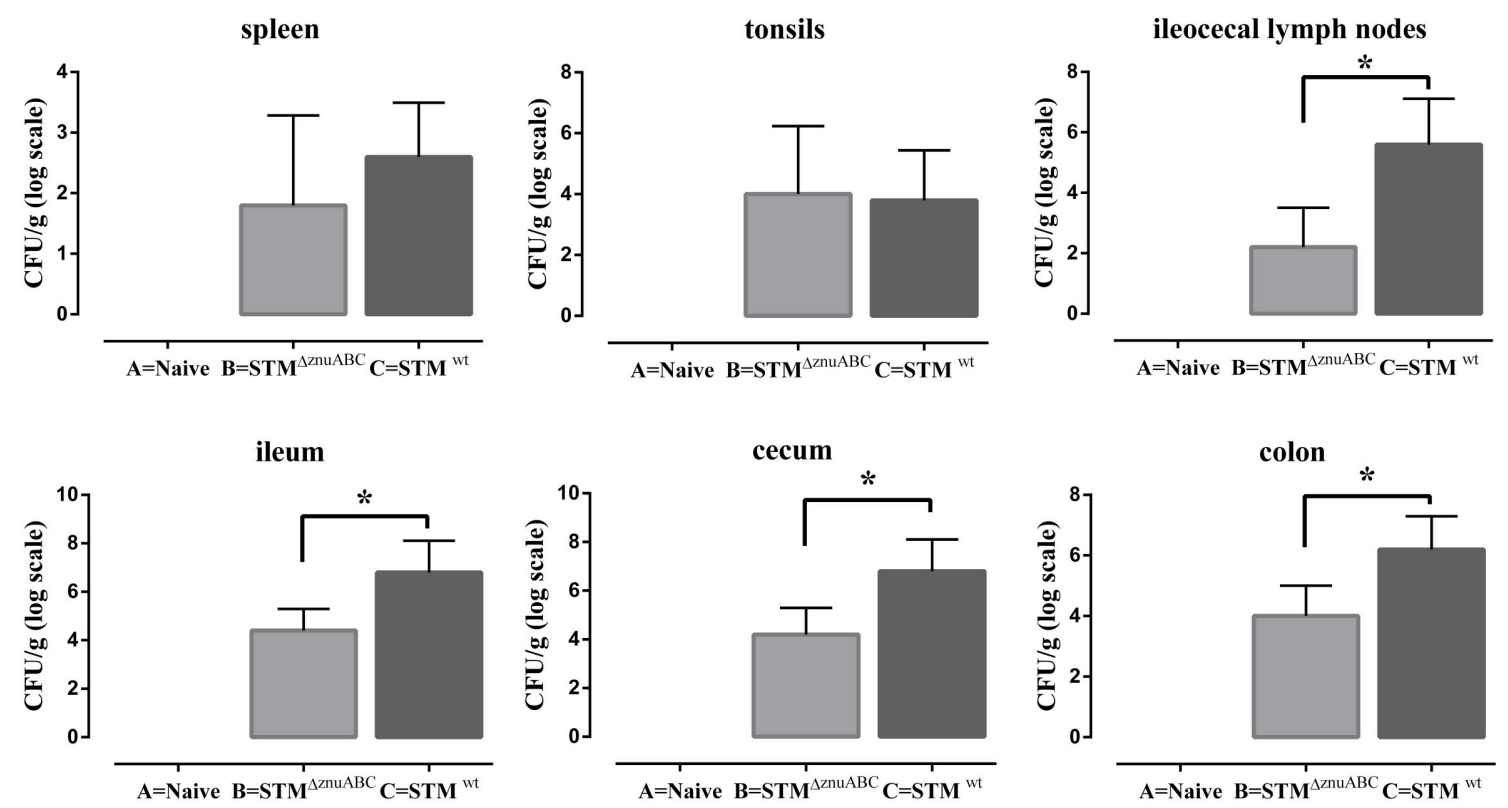

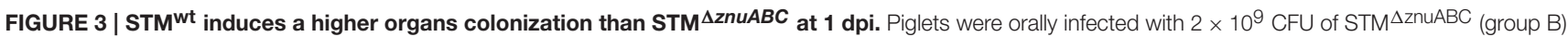
or STMwt (group C), and bacterial burdens were determined at 1 dpi. Differences between groups B and C were estimated using non-parametric Mann-Whitney test and were considered significant when ${ }^{*} P \leq 0.05$. Organ samples taken from naïve animals (group A) were negative. Error bars represent one SD from the mean.
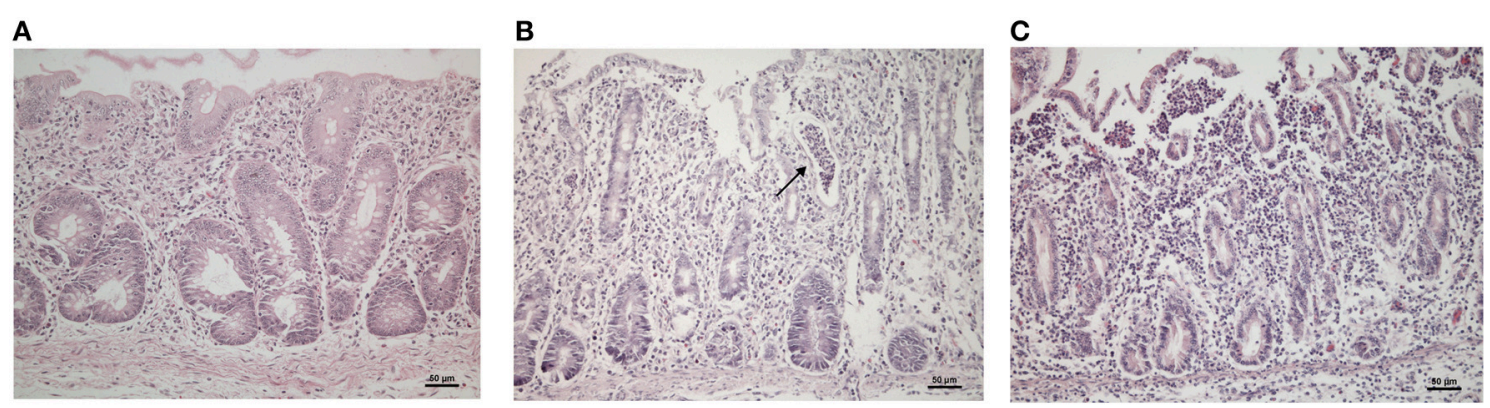

FIGURE 4 | (A-C) Photomicrographies showing histological changes of the cecum. (A) Naïve control piglets; (B) piglets infected with STM $\Delta$ znuABC: multifocal and moderate neutrophilic infiltrate (arrows), crypt abscess formation; (C) piglets infected with STMwt: marked and diffuse neutrophilic infiltration.

B $(p<0.001)$ and $\mathrm{C}(p<0.001)$ in the cecal content and in group $\mathrm{B}(p<0.05)$ in the colonic one when compared to group A (naive; Figure 6B; Supplementary Figure 5B). The levels of the Enterobacteriaceae other than Salmonella decreased significantly in both groups of animals infected with Salmonella strains in the cecal and colonic contents at $12 \mathrm{dpi}$ (Figure 6B; Supplementary Figure 5B). A higher level of Salmonella, consistent with the microbiological findings, was observed in group C $\left(S T M^{\mathrm{wt}}\right)$ compared to group B $\left(\mathrm{STM}^{\triangle \mathrm{znuABC}}\right)$ in all the intestinal samples, while Salmonella was never detected in group A (naïve; Figure 6; Supplementary Figures 4, 5).

These results show that $S$. Thyphimurium is able to alter intestinal microbiota in pigs inducing modifications correlated to its virulence.

\section{Bacterial Diversity of the Fecal Microbiota after Salmonella Infection}

Massive parallel sequencing of the $16 \mathrm{~S}$ rDNA hypervariable V3-V4 region was performed on fecal samples available from the three experimental groups A, B, and C. The sequencing yielded a total of 177198 reads passing quality control (median reads per sample 11030). OTU classification yielded a median of 5742 OTUs per sample. Sequencing reads are available at http://www.ncbi.nlm.nih.gov/bioproject/ PRJNA302126 (BioProject accession ID: PRJNA302126).

We evaluated the bacterial diversity of the fecal microbiota associated with Salmonella strains by estimating alpha- and betadiversity. Shannon index demonstrated that the fecal microbiota diversity in piglets infected with $\mathrm{STM}^{\triangle \mathrm{znuABC}}$ (group B) and 


\section{CECUM}
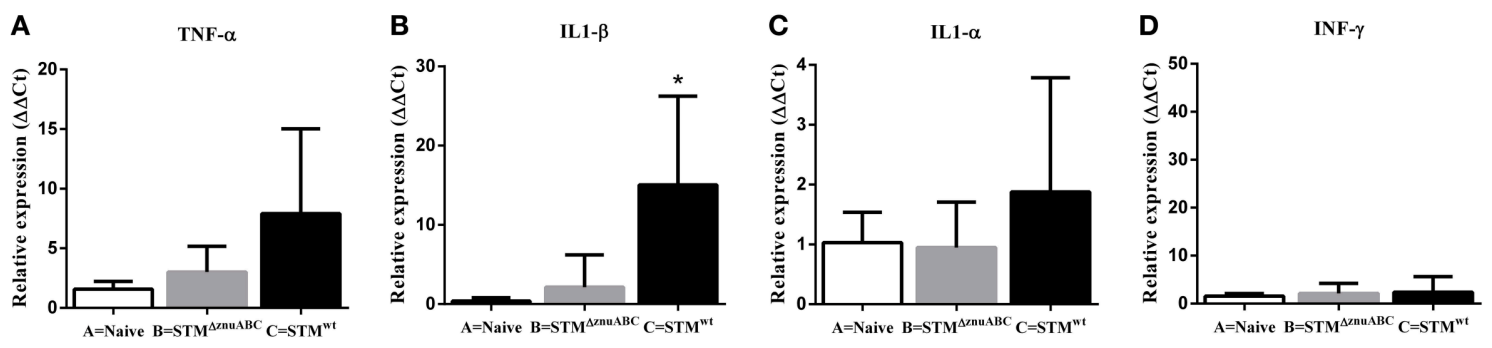

\section{1 dpi}
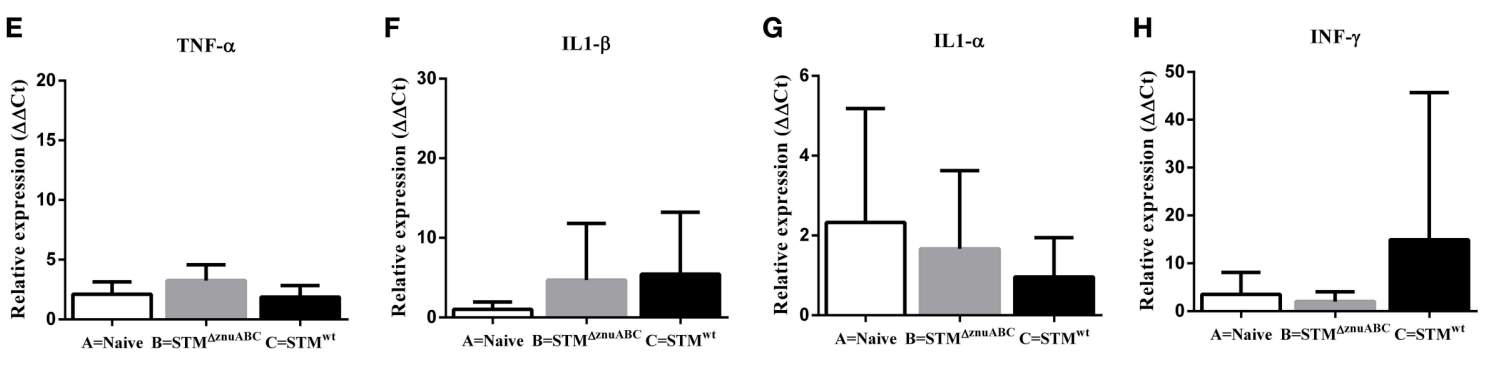

\section{2 dpi}

FIGURE 5 | (A-H) Cytokines expression reveals that unlike STMWt, STM ${ }^{\triangle 2 n u A B C}$ strain is not able to induce a strong host immune response. TNF- $\alpha$, IL1- $\alpha$, IL1- $\beta$, and INF- $\gamma$ expression was measured in the cecum at 1 and 12 dpi by real time RT-PCR. Gray bars and black bars represent STM ${ }^{\Delta \text { znuABC }}$-infected (group B) and STM ${ }^{W t}$-infected piglets (group C), respectively. The asterisk indicates statistical significance ${ }^{\star} P \leq 0.05$, Mann-Whitney test.
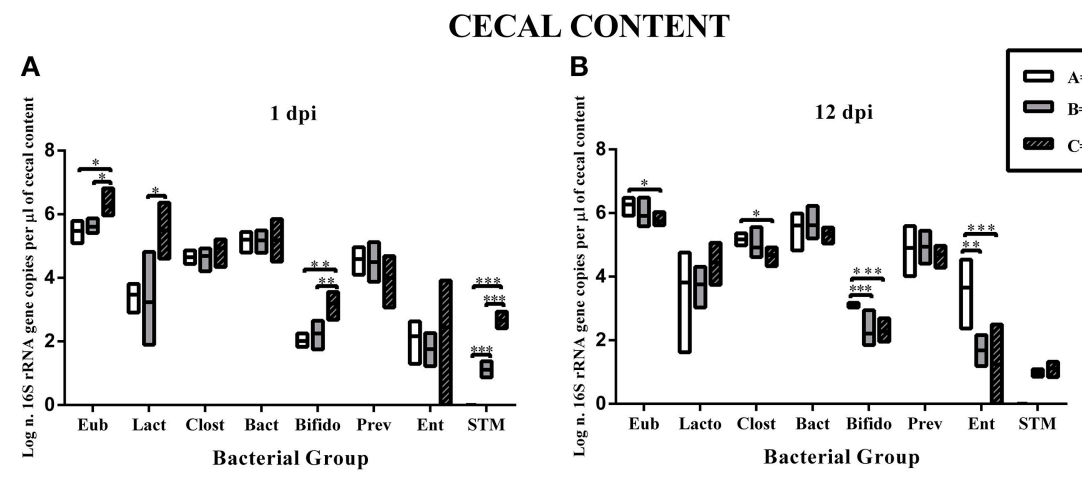

FIGURE 6 | STM ${ }^{\text {wt }}$ and STM ${ }^{\Delta z n u A B C}$ differently modify cecal microbiota of piglets. Piglets were sacrificed at 1 and 12 dpi (A,B). Bacterial genomic DNA was isolated from cecal content and $\mathrm{PPCR}$ analysis measured the abundance of specific commensal bacterial groups. White bars represent uninfected controls (group A).

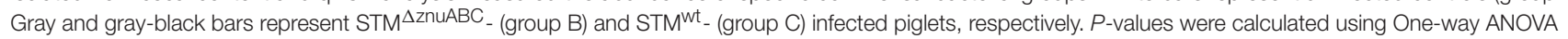
with Bonferroni's post-test. Significant differences between groups are indicated by ${ }^{\star} P \leq 0.05,{ }^{* *} P \leq 0.01$, and ${ }^{* * *} P \leq 0.001$. Eub, all bacteria; Lacto,

Lactobacillus/Lactococcus group; Clost, Eubacterium rectale/Clostridium coccoides; Bact, Bacteroides sp.; Bifido, Bifidobacterium; Prev, Prevotellaceae; Ent,

Enterobacteriaceae other than Salmonella; STM, S. Typhimurium.

STM $^{\text {wt }}$ (group C) was significantly higher than the naïve animals (group A), at 0 and at 2 dpi respectively ( $p<0.01$ ). However, group $\mathrm{C}$ showed a significant lower alfa diversity at $12 \mathrm{dpi}$ than group A (Figure 7A). Using Fisher's alpha, an index not influenced by the sample size and less affected by the abundance of the most common species than Shannon's index, we found a higher diversity in piglets belonging to group $\mathrm{C}$ compared to group B at 2 dpi $(p<0.05)$. At the same time, Fisher's alpha confirmed the significant lower alfa diversity in group $C$ at $12 \mathrm{dpi}$ compared to group A $(p<0.05$; Figure $7 \mathbf{B})$.

The beta diversity was calculated using both unweighted Unifrac and Bray-Curtis dissimilarity; principal component analysis (PCoA) was performed. As shown in Figure 8A, using Unifrac, four out of five samples belonging to group $C\left(S_{T M}{ }^{\mathrm{wt}}\right)$ 

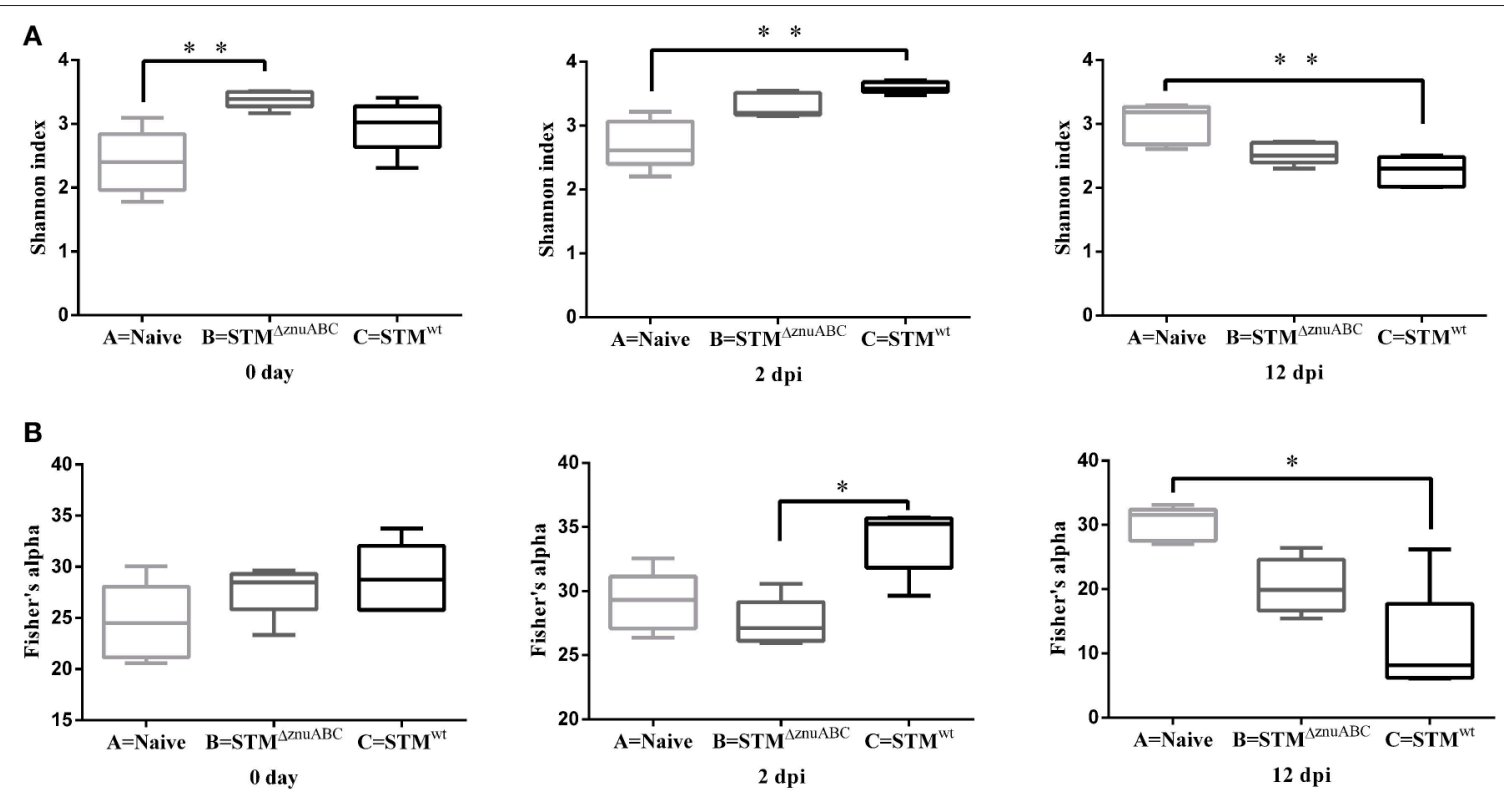

FIGURE 7 | Structural comparison of fecal microbiota among groups A, B, and C. The Shannon index (A) and Fisher's alpha (B) were used to estimate diversity of the fecal microbiota in naïve animals (group A) and in STM $\triangle$ ZnUABC - (group B) and STM ${ }^{\text {wt }}$ - (group C) infected piglets. Boxes represent median, and first and third quartiles; whiskers indicate minimum and maximum values. The asterisks indicate statistical significance ${ }^{*} P \leq 0.05$ and ${ }^{* *} P \leq 0.01$, Dunn's test.

clustered separately along the principal coordinate 1 (PCA1) at 12 dpi. In addition, a clear separation of group B (STM $\left.{ }^{\triangle \mathrm{znuABC}}\right)$ from the rest of the samples is noticeable along the principal coordinate 2 (PCA2). The PCoA using Bray-Curtis dissimilarity did not allow any clear separation of the groups, although all the five samples belonging to group C $\left(\mathrm{STM}^{\mathrm{wt}}\right)$, at $2 \mathrm{dpi}$, clustered at the extreme right along the principal coordinate 1 (PCA1; Figure 8B). On the light of these data, it can inferred that Shannon and Unifrac results, in which it seem to be differences among groups at time 0 , could be biased by small sample size. Therefore, the microbiota composition of the different groups could be considered similar at time 0 .

\section{Salmonella Strains-Associated Alterations in Fecal Microbiota by NGS}

In order to compare how the composition of the fecal bacteria differed among treatment groups, the Kruskal-Wallis test and the Benjamini-Hochberg FDR method were used to identify differentially abundant taxa. Genus-level normalized data are available in Supplementary Table 3. The distribution of reads into phyla revealed that the bacterial communities of all samples consisted primarily of Firmicutes and Bacteroidetes. Microbiota analysis showed that 7 phyla, 112 families, 404 genera, and 15 phyla, 143 families, and 719 genera differed across groups A, B, and C, respectively at 2 and 12 dpi (see Supplementary Table 4). Figures 9A,B and Supplementary Figure 6 represent heatmaps showing the genus-level clustering according to frequency within each sample (abundance ratio greater than 0.1 ) at times 0,2 , and $12 \mathrm{dpi}$; abundant genera were color coded red, and white color coding indicated missing genera. The most remarkable difference reported in the piglets infected with STM ${ }^{\text {wt }}$ (group C) compared with naïve (group A) is that they showed an abundant presence of lactic acid-producing bacteria and a reduction of short chain fatty acids (SCFAs)-producing bacteria (Figures 9A,B). Analysis of data also revealed that piglets infected with STM ${ }^{\text {wt }}$ (group C) initially showed a decrease in Prevotella at 2 dpi compared to the naive (group A). In addition, at $12 \mathrm{dpi}$, a more abundant presence of Prevotella, Phascolarcobacterium, and Eubacterium was evident in group $\mathrm{C}\left(\mathrm{STM}^{\mathrm{wt}}\right)$ rather than in groups $\mathrm{A}$ and $\mathrm{B}$.

Moreover, clustering analysis highlighted the differences in the sample distributions according to the treatment type. At $2 \mathrm{dpi}$, the most represented genera displayed a perfect clusterization of each single sample into its belonging study group (Figure 9A). Similarly, at $12 \mathrm{dpi}$, each piglet grouped into its belonging treatment group, except 2 samples (5 and 12) clustered in a different study group (Figure 9B). Moreover, at 12 dpi, groups A (naïve) and B $\left(S_{T M}{ }^{\triangle \mathrm{znuABC}}\right)$ are more similar to each other, while group C $\left(\mathrm{STM}^{\mathrm{wt}}\right)$ featured more relevant effects (Figure 9B). No significant differences were detected when each single group was analyzed longitudinally according to the three collection times. These data show that infection with different strains of S. Typhimurium is associated with different alterations of fecal microbiota.

\section{DISCUSSION}

The importance of pigs as a source of Salmonella in the food chain is well-known. However, while Salmonella pathogenicity has been widely studied in mice, our knowledge on the modality of interaction of this pathogen with pigs is still limited. It has been known that different and multiple factors can influence the dynamics of Salmonella colonization in swine, including 


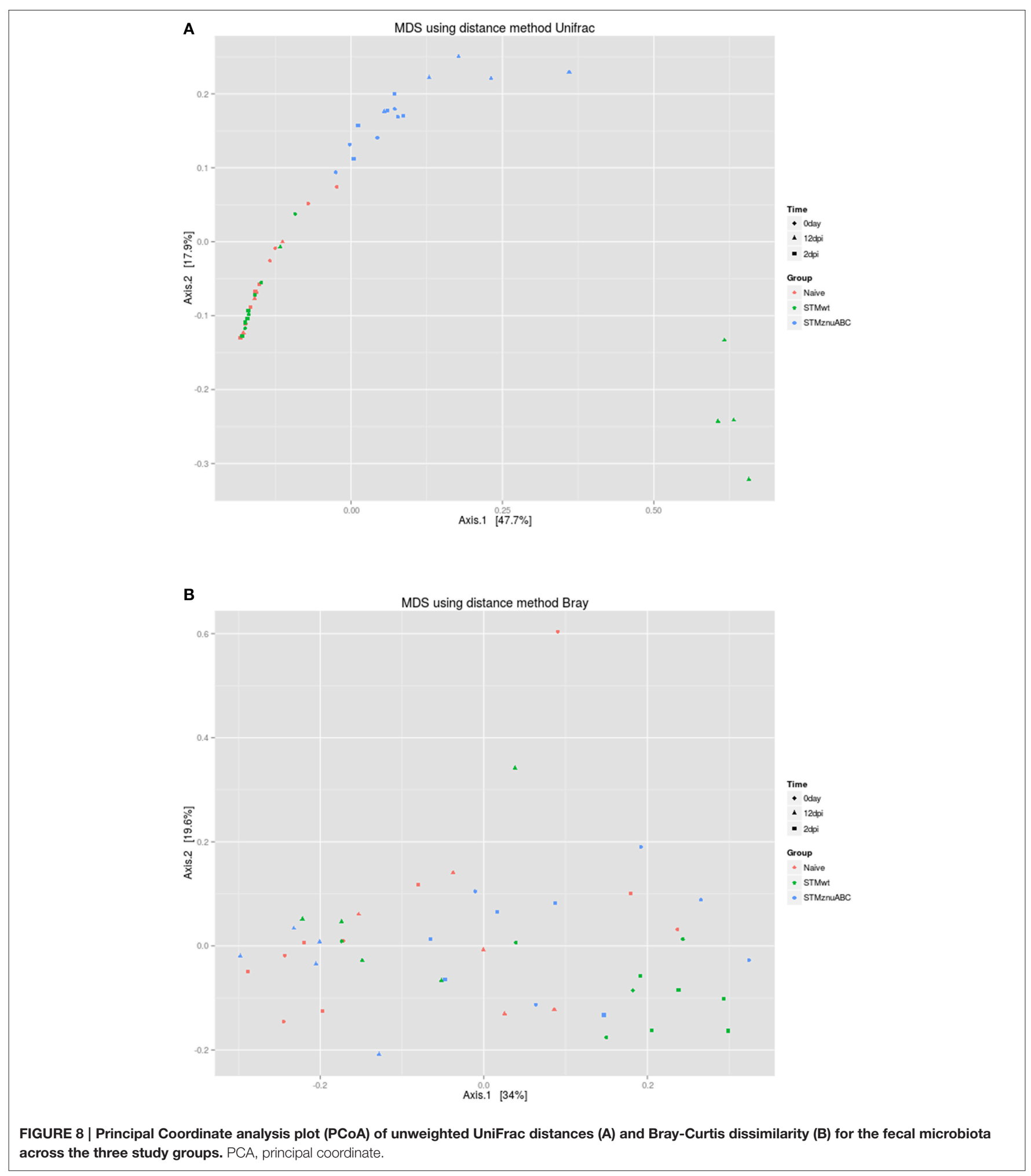

pathogen features (virulence mechanisms, exposure dosage), pig immune responses and the complex interplay between the pathogen and the intestinal microbiota (Bearson et al., 2013). In this study, we used a post-weaned piglet model to compare differences in the host colonization, inflammatory response, and modification of the intestinal microbiota induced by STM ${ }^{\mathrm{wt}}$ and $\mathrm{STM}^{\triangle \mathrm{znuABC}}$ in order to elucidate the interplay among host, pathogen and gut microbiota. STM ${ }^{\triangle \mathrm{znuABC}}$ was chosen due to the fact that our previous studies have revealed that this strain is strongly attenuated either in mice or in pigs (Ammendola et al., 
A
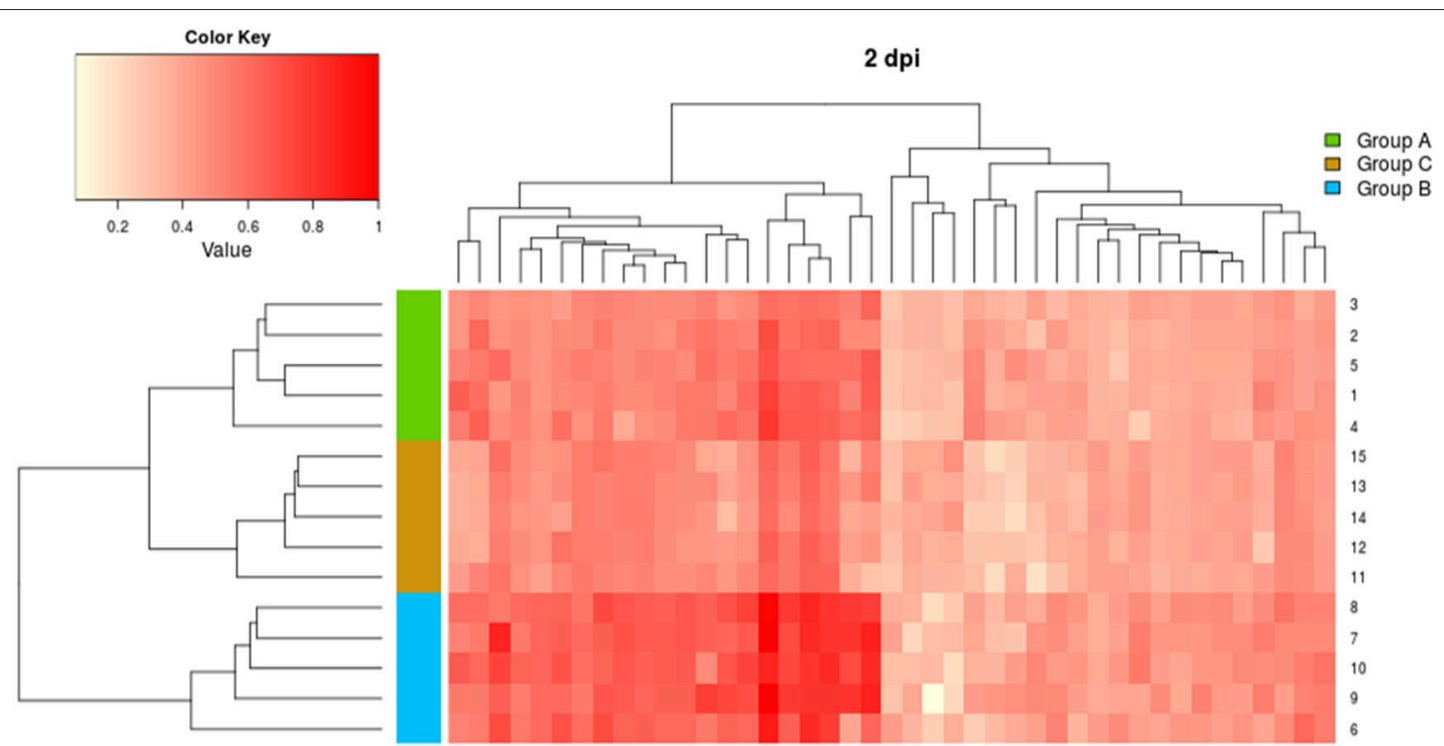

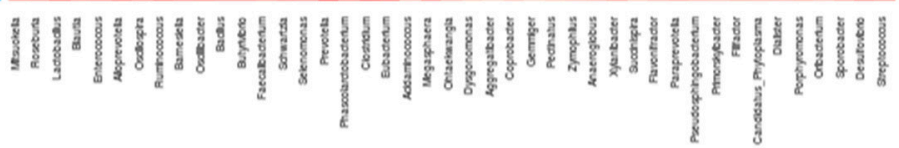

Genus

B
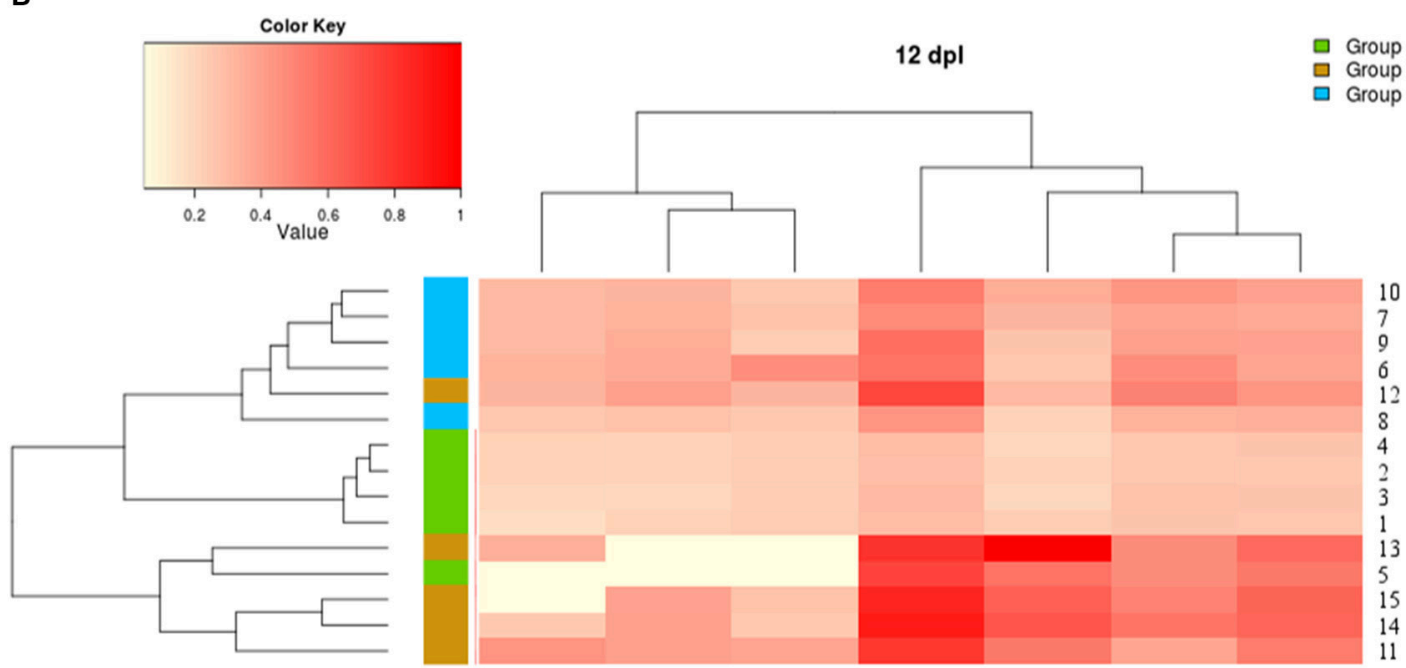

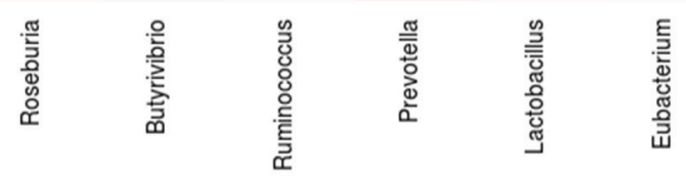

Genus

FIGURE 9 | (A,B) Heatmap indicating genus-level changes in the microbiota composition of piglets Naïve (group A), and piglets infected with STM ${ }^{\Delta \text { znuABC }}$ (group B) or with STM ${ }^{w t}$ (group C) at 2 and 12 dpi. The relative abundance of the most represented genera is indicated by a gradient of color from white (low abundance) to red (high abundance). The hierarchical clustering analysis of the samples, based on the similarity of the microbiota composition, are displayed on the left. Animals 1-5:

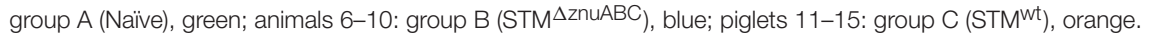


2007; Pasquali et al., 2008; Pesciaroli et al., 2013). Moreover, studies carried out in a mouse model showed that ZnuABCmediated zinc uptake confers resistance to the antimicrobial protein calprotectin and promotes Salmonella growth over the competing intestinal microbiota (Liu et al., 2012).

Here, we demonstrate that a different organs colonization, intestinal inflammation and modification of porcine microbiota are correlated with the different virulence of Salmonella strains. The inflammatory response evaluated through the expression of the immune mediators, and corroborated by histological findings, has shown that STM ${ }^{\mathrm{wt}}$ induces a prompt increase of serum markers of inflammation during the early stage of infection (1 dpi). Moreover, at the same time point, the expression of tissue-associated markers showed a tendency to increase even if only IL1- $\beta$ in cecum and colon $(p<0.01)$ and IL1- $\alpha$ in ileocecal lymph nodes $(p<0.01)$ reach statistical significance. The prompt induction of host response could be due to the rapid and high-level replication of STM ${ }^{\mathrm{wt}}$ as showed by our microbiological data. On the contrary, at $1 \mathrm{dpi}$, the histological and immunological analysis revealed a mild intestinal inflammation and a poor systemic response induced by $\mathrm{STM}^{\triangle \mathrm{znuABC}}$ confirming characteristics of attenuation in growth and virulence of this strain. As a whole, these observations indicate that the host is able to mount a rapid innate immune response following Salmonella infection within a few hours after gut colonization. The magnitude of the response and the severity of the clinical manifestations provide evidence that the host response and lesions are correlated and dependent to $S$. Typhimurium virulence.

It is known that, similarly to what happens in vitro and in murine models of infection (Barthel et al., 2003; Stecher et al., 2007; Barman et al., 2008), S. Typhimurium strains induce an acute inflammatory response in the intestinal mucosa also in piglets (Bearson et al., 2013). Several studies have proved how S. Typhimurium takes advantages of inflammation to compete with the resident microbiota and to colonize the inflamed gut in mice (Lupp et al., 2007; Stecher et al., 2007; Barman et al., 2008; Winter et al., 2010) and piglets (Chirullo et al., 2015). In our study, we investigated the impact of S. Typhimurium on the porcine intestinal microbial communities. We found that S. Typhimurium infection modifies either the number or the composition of gut resident bacteria. In particular, these changes were associated with STM ${ }^{\mathrm{wt}}$, while the attenuated STM $\triangle$ znuABC seemed to be less fit to sustain competition with the microbiota. These observations are in agreement with the studies performed in mice, where attenuated Salmonella mutants do not colonize intestine as well as wild-type strains as they are not able to trigger an efficient inflammatory response (Stecher et al., 2007; Lawley et al., 2008; Raffatellu et al., 2009; Winter et al., 2010).

The major changes in the microbiota composition are mainly related to the significantly more abundant presence of Lactobacillus/Lactococcus group after STM ${ }^{\text {wt }}$ infection. This observation is in agreement with the results obtained by Videnska et al. (2013), which showed a significant increase of Lactobacillaceae in chicken cecal microbiota after $S$. Enteritidis infection. A possible explanation could be attributable to the microaerophilic growth of Lactobacilli, which may allow them to survive under conditions of increased redox potential due to the production of reactive oxygen species by granulocytes infiltrating the site of inflammation as occurs in a highly inflamed gut (Videnska et al., 2013). Indeed, there is evidence that lactic acid accumulation could contribute to impair the intestinal defense barrier and increase the osmotic load in the intestinal lumen (Ling et al., 2014). The utilization of next-generation high-throughput sequencing allowed a wider description of the intestinal microbiota. In our study, clustering analysis shows that the microbiota composition changed after infection with Salmonella strains and the characteristics of the modifications were correlated with the virulence of the strain used. Our analysis reveals a different abundance of the most represented genera in piglets infected with STM ${ }^{\text {wt }}$ when compared with $\mathrm{STM}^{\triangle \mathrm{znuABC}}$ and naïve piglets. In fact, microbiota of piglets infected with $S_{T M}{ }^{\mathrm{wt}}$ was characterized by an overall reduction of SCFA-producing bacteria (Ruminococcaceae including Faecalibacterium, Roseburia, Butyrivibrio, and Clostridium genera). SCFAs such as acetate and butyric acid are produced by microbial fermentation of carbohydrates and provide beneficial immunomodulatory and anti-inflammatory properties (Ling et al., 2014). In particular, butyric acid contributes to the inhibition of Salmonella in an acidic environment (Bearson et al., 2006), decreases invasion of intestinal cells by down-regulating expression of Pathogenicity island 1 (Gantois et al., 2006) and reduces the Salmonella-induced proinflammatory response of enterocytic cells in vitro (Malago et al., 2005). In line with these observations, previous studies showed that Faecalibacterium, which is correlated with butyrate production, also exhibits anti-inflammatory effects counterbalancing intestinal microbiota dysbiosis (Sokol et al., 2008). Hence, the reduced abundance of SCFA-producing bacteria induced by STM $^{\mathrm{wt}}$ could explain the enhanced inflammatory status observed in the gastrointestinal tract of piglets treated with this Salmonella strain; and it could be of interest to investigate the mechanisms leading to a reduction of this potentially protective component of the intestinal microbiota. Moreover, upon infection with Salmonella strains, microbiota composition also showed changes in Prevotella, Phascolarcobacterium and Eubacterium. Similarly to what elsewhere reported (Bearson et al., 2013), we observed a decrease of Prevotella in piglets infected with STM ${ }^{\mathrm{wt}}$ at 2 dpi. However the limitation of available information about the biological function of such genera makes difficult to extrapolate any significant meaning to our findings. At the same time it should be acknowledged that the alpha and beta diversity patterns across the three groups within the three time points analyzed presented several discrepancies that can be attributable to the sensitivity of the next-generation sequencing technology and to the relative small sample size. However, both alpha-diversity indices converge on a significant lower alpha-diversity in group $\mathrm{C}$ compared to group A at dpi 12. At the same time, the significant difference found in the whole microbiome composition at time 0 between group A and group B, highlighted by Shannon alpha index and Unifrac beta-diversity PCoA, may raise the possibility that the inability of the mutant strain to colonize the intestine could be related to the composition of the microflora. Although we cannot discard this hypothesis, the present data does not 
allow any speculation and further studies using a larger sample size and, possibly, a more detailed time-course is warranted. Overall, our data show that the results of the interaction among Salmonella, the intestinal microbiota and the gut response are influenced by the specific characteristics of the three factors. The virulence of Salmonella and the alteration of microbiota composition is crucial in determining the outcome of the infection.

\section{AUTHOR CONTRIBUTIONS}

RD planned and performed the research, analyzed data and wrote the manuscript. PP designed and planned the research, participated to the interpretation and discussion of the results, and revised the paper; CM planned and performed the research, analyzed data and revised the manuscript. MP, BC, and MT performed part of the research and revised the manuscript. GA, JR, and NM performed part of the research. SA and AB revised the manuscript. GG revised the manuscript. GP and LM performed part of the research and contributed to the analysis of the data. EM and SP performed histological analysis. VN and

\section{REFERENCES}

Ahmer, B. M. M., and Gunn, J. S. (2011). Interaction of Salmonella Spp. with the intestinal microbiota. Front. Microbiol. 2:101. doi: 10.3389/fmicb.2011.00101

Ammendola, S., Pasquali, P., Pistoia, C., Petrucci, P., Petrarca, P., Rotilio, G., et al. (2007). High-affinity $\mathrm{Zn} 2+$ uptake system $\mathrm{ZnuABC}$ is required for bacterial zinc homeostasis in intracellular environments and contributes to the virulence of Salmonella enterica. Infect. Immun. 75, 5867-5876. doi: 10.1128/IAI.00559-07

Barman, M., Unold, D., Shifley, K., Amir, E., Hung, K., Bos, N., et al. (2008). Enteric Salmonellosis disrupts the microbial ecology of the murine gastrointestinal tract. Infect. Immun. 76, 907-915. doi: 10.1128/IAI.01432-07

Barthel, M., Hapfelmeier, S., Quintanilla-Martínez, L., Kremer, M., Rohde, M., Hogardt, M., et al. (2003). Pretreatment of mice with streptomycin provides a Salmonella enterica serovar Typhimurium colitis model that allows analysis of both pathogen and host. Infect. Immun. 71, 2839-2858. doi: 10.1128/IAI.71.5.2839-2858.2003

Bearson, S. M., Allen, H. K., Bearson, B. L., Looft, T., Brunelle, B. W., Kich, J. D., et al. (2013). Profiling the gastrointestinal microbiota in response to Salmonella: low versus high Salmonella shedding in the natural porcine host. Infect. Genet Evol. 16, 330-340. doi: 10.1016/j.meegid.2013.03.022

Bearson, S. M., Bearson, B. L., and Rasmussen, M. A. (2006). Identification of Salmonella enterica serovar Typhimurium genes important for survival in the swine gastric environment. Appl. Environ. Microbiol. 72, 2829-2836. doi: 10.1128/AEM.72.4.2829-2836.2006

Behnsen, J., Perez-Lopez, A., Nuccio, S. P., and Raffatellu, M. (2015). Exploiting Host immunity: the Salmonella paradigm. Trends Immunol. 36, 112-120. doi: 10.1016/j.it.2014.12.003

Bogomolnaya, L. M., Andrews, K. D., Talamantes, M., Maple, A., Ragoza, Y., Vazquez-Torres, A., et al. (2013). The ABC-type efflux pump MacAB protects Salmonella enterica serovar typhimurium from oxidative stress. MBio 4, e00630-e00613. doi: 10.1128/mBio.00630-13

Caporaso, J. G., Kuczynski, J., Stombaugh, J., Bittinger, K., Bushman, F. D., Costello, E. K., et al. (2010). QIIME allows analysis of highthroughput community sequencing data. Nat Methods 7, 335-336. doi: 10.1038/nmeth.f.303

Caporaso, J. G., Lauber, C. L., Walters, W. A., Berg-Lyons, D., Huntley, J., Fierer, N., et al. (2012). Ultra-high-throughput microbial community analysis on the Illumina HiSeq and MiSeq platforms. ISME J. 6, 1621-1624. doi: 10.1038/ismej. 2012.8
MP performed next-generation sequencing and analyzed data. PP and CP contributed to perform technical experiments.

\section{FUNDING}

This work was supported by ISS intramural research funds and by Transnational Research Project EMIDA ERA-NET "HealthyGut-Multi-focal strategies to improve gut health and reduce enteritis in poultry and pigs"(MIPAF-DM 27373/7303/2010).

\section{ACKNOWLEDGMENTS}

We thank Massimiliano Francia for technical assistance.

\section{SUPPLEMENTARY MATERIAL}

The Supplementary Material for this article can be found online at: http://journal.frontiersin.org/article/10.3389/fcimb. 2015.00106

Chirullo, B., Pesciaroli, M., Drumo, R., Ruggeri, J., Razzuoli, E., Pistoia, C., et al. (2015). Salmonella typhimurium exploits inflammation to its own advantage in a porcine enteritis model. Front. Microbiol. 6:985. doi: 10.3389/fmicb.2015.00985

Elfenbein, J. R., Johanna, R., Endicott-Yazdani, T., Porwollik, S., Bogomolnaya, L. M., Cheng, P., et al. (2013). Novel determinants of intestinal colonization of Salmonella enterica serotype typhimurium identified in bovine enteric infection. Infect. Immun. 81, 4311-4320. doi: 10.1128/IAI.00874-13

Funk, J., and Gebreyes, W. A. (2004). Risk factors associated with Salmonella prevalence on swine farms. J. Swine Health Prod. 12, 246-251.

Gantois, I., Ducatelle, R., Pasmans, F., Haesebrouck, F., Hautefort, I., Thompson, A., et al. (2006). Butyrate specifically down-regulates salmonella pathogenicity island 1 gene expression. Appl. Environ. Microbiol. 72, 946-949. doi: 10.1128/AEM.72.1.946-949.2006

Hallstrom, K., and McCormick, B. A. (2011). Salmonella interaction with and passage through the intestinal mucosa: through the lens of the organism. Front. Microbiol. 2:88. doi: 10.3389/fmicb.2011.00088

Hohmann, E. L. (2001). Nontyphoidal salmonellosis. Clin. Infect. Dis. 32, 263-269. doi: $10.1086 / 318457$

Juricova, H., Videnska, P., Lukac, M., Faldynova, M., Babak, V., Havlickova, H., et al. (2013). Influence of Salmonella enterica serovar enteritidis infection on the development of the cecum microbiota in newly hatched chicks. Appl. Environ. Microbiol. 79, 745-747. doi: 10.1128/AEM.02628-12

Lawley, T. D., Bouley, D. M., Hoy, Y. E., Gerke, C., Relman, D. A., and Monack, D. M. (2008). Host transmission of Salmonella enterica serovar Typhimurium is controlled by virulence factors and indigenous intestinal microbiota. Infect. Immun. 76, 403-416. doi: 10.1128/IAI.01189-07

Ling, Z., Liu, X., Jia, X., Cheng, Y., Luo, Y., Yuan, L., et al. (2014). Impacts of infection with different toxigenic Clostridium difficile strains on faecal microbiota in children. Sci. Rep. 4:7485. doi: 10.1038/srep07485

Littman, D. R., and Pamer, E. G. (2011). Role of the commensal microbiota in normal and pathogenic host immune responses. Cell Host Microbe 10, 311-323. doi: 10.1016/j.chom.2011.10.004

Liu, J. Z., Jellbauer, S., Poe, A. J., Ton, V., Pesciaroli, M., Kehl-Fie, T. E., et al. (2012). Zinc sequestration by the neutrophil protein calprotectin enhances Salmonella growth in the inflamed gut. Cell Host Microbe 11, 227-239. doi: 10.1016/j.chom.2012.01.017

Lupp, C., Robertson, M. L., Wickham, M. E., Sekirov, I., Champion, O. L., Gaynor, E. C., et al. (2007). Host-mediated inflammation disrupts the intestinal 
microbiota and promotes the overgrowth of Enterobacteriaceae. Cell Host Microbe 2, 204. doi: 10.1016/j.chom.2007.08.002

Malago, J. J., Koninkx, J. F., Tooten, P. C., van Liere, E. A., and van Dijk, J. E. (2005). Anti-inflammatory properties of heat shock protein 70 and butyrate on Salmonella-induced interleukin-8 secretion in enterocyte-like Caco- 2 cells. Clin. Exp. Immunol. 141, 62-71. doi: 10.1111/j.1365-2249.2005.02810.x

Pasquali, P., Ammendola, S., Pistoia, C., Petrucci, P., Tarantino, M., Valente, C., et al. (2008). Attenuated Salmonella enterica serovar Typhimurium lacking the ZnuABC transporter confers immune-based protection against challenge infections in mice. Vaccine 26, 3421-3426. doi: 10.1016/j.vaccine.2008. 04.036

Pesciaroli, M., Gradassi, M., Martinelli, N., Ruggeri, J., Pistoia, C., Raffatellu, M., et al. (2013). Salmonella Typhimurium lacking the Znuabc transporter is attenuated and immunogenic in pigs. Vaccine 31, 2868-2873. doi: 10.1016/j.vaccine.2013.04.032

Pires, S. M., de Knegt, L., and Hald, T. (2011). Estimation of the Relative Contribution of Different Food and Animal Sources to Human Salmonella Infections in the European Union. European Food Safety Authority. Available online at: http://www.efsa.europa.eu/en/supporting/doc/184e.pdf

Raffatellu, M., George, M. D., Akiyama, Y., Hornsby, M. J., Nuccio, S. P., Paixao, T. A., et al. (2009). Lipocalin-2 resistance confers an advantage to Salmonella enterica serotype Typhimurium for growth and survival in the inflamed intestine. Cell Host Microbe 5, 476-486. doi: 10.1016/j.chom.2009.03.011

Santos, R. L., Raffatellu, M., Bevins, C. L., Adams, L. G., Tükel, C., Tsolis, R. M., et al. (2009). Life in the inflamed intestine, Salmonella Style. Trends Microbiol. 17, 498-506. doi: 10.1016/j.tim.2009.08.008

Sassone-Corsi, M., and Raffatellu, M. (2015). No Vacancy: How beneficial microbes cooperate with immunity to provide colonization resistance to pathogens. $J$ Immunol. 194, 4081-4087. doi: 10.4049/jimmunol.1403169

Sokol, H., Pigneur, B., Watterlot, L., Lakhdari, O., Bermúdez-Humarán, L. G., Gratadoux, J. J., et al. (2008). Faecalibacterium prausnitzii is an antiinflammatory commensal bacterium identified by gut microbiota analysis of
Crohn disease patients. Proc. Natl. Acad. Sci. U.S.A. 105, 16731-16736. doi: 10.1073/pnas.0804812105

Stecher, B., Robbiani, R., Walker, A. W., Westendorf, A. M., Barthei, M., Kremer, M., et al. (2007). Salmonella enterica serovar Typhimurium exploits inflammation to compete with the intestinal microbiota. PLoS Biol. 5:e244. doi: 10.1371/journal.pbio.0050244

Videnska, P., Sisak, F., Havlickova, H., Faldynova, M., and Rychlik, I. (2013). Influence of Salmonella enterica serovar Enteritidis infection on the composition of chicken cecal microbiota. BMC Vet. Res. 9:140. doi: 10.1186/1746-6148-9-140

Whelan, J. A., Russell, N. B., and Whelan, M. A. (2003). A method for the absolute quantification of cDNA using real-time PCR. J. Immunol. Methods 278, 261-269. doi: 10.1016/S0022-1759(03)00223-0

Winter, S. E., Sebastian, E., Winter, M. G., Godinez, I., Yang, H. J., Rüssmann, H., et al. (2010). A rapid change in virulence gene expression during the transition from the intestinal lumen into tissue promotes systemic dissemination of Salmonella. PLoS Pathog. 6:e1001060. doi: 10.1371/journal.ppat.1001060

Zhang, Q., Widmer, G., and Tzipori, S. (2013). A pig model of the human gastrointestinal tract. Gut Microbes 4, 193-200. doi: 10.4161/gmic.23867

Conflict of Interest Statement: The authors declare that the research was conducted in the absence of any commercial or financial relationships that could be construed as a potential conflict of interest.

Copyright (C) 2016 Drumo, Pesciaroli, Ruggeri, Tarantino, Chirullo, Pistoia, Petrucci, Martinelli, Moscati, Manuali, Pavone, Picciolini, Ammendola, Gabai, Battistoni, Pezzotti, Alborali, Napolioni, Pasquali and Magistrali. This is an open-access article distributed under the terms of the Creative Commons Attribution License (CC BY). The use, distribution or reproduction in other forums is permitted, provided the original author(s) or licensor are credited and that the original publication in this journal is cited, in accordance with accepted academic practice. No use, distribution or reproduction is permitted which does not comply with these terms. 